Evaluation of activation parameters of activated carbon from coffee and cocoa seed husk rests: carbon yields and $\mathrm{Ni}(\mathrm{II})$ adsorption capacity study Peer-reviewed author version

HERNANDEZ RODRIGUEZ, Monica; YPERMAN, Jan; CARLEER, Robert; MAGGEN, Jens; VANDERHEYDEN, Sara; Falcon Hernandez, Jose; Otero Calvis, Alexis \& Gryglewicz, Grazyna (2018) Evaluation of activation parameters of activated carbon from coffee and cocoa seed husk rests: carbon yields and $\mathrm{Ni}(\mathrm{II})$ adsorption capacity study. In: DESALINATION AND WATER TREATMENT, 104, p. 175-188.

DOI: $10.5004 / d w t .2018 .21907$

Handle: http://hdl.handle.net/1942/27973 


\title{
Evaluation of activation parameters of activated carbon from coffee and cocoa seed husk rests: carbon yields and $\mathrm{Ni}(\mathrm{II})$ adsorption capacity study
}

\author{
Mónica Hernández Rodríguez ${ }^{\mathrm{a}, \mathrm{c}}$, Jan Yperman ${ }^{\mathrm{b} *}$, Robert Carleer ${ }^{\mathrm{b}}$, Jens Maggen ${ }^{\mathrm{b}}$, Sara Vanderheyden ${ }^{\mathrm{b}}$, José \\ Falcón Hernández ${ }^{\mathrm{c}}$, Alexis Otero Calvis ${ }^{\mathrm{a}}$, Grazyna Gryglewicz ${ }^{\mathrm{d}}$ \\ ${ }^{a}$ Mineral and Metallurgic Institute (ISMM), Moa, Holguín, Cuba; mhernandezr@ismm.edu.cu; aotero@ismm.edu.cu; \\ ${ }^{\mathrm{b}}$ Research group of Applied and Analytical Chemistry, Hasselt University, Agoralaan building D, 3590-Diepenbeek, \\ Belgium; jan.yperman@uhasselt.be; $\quad$ robert.carleer@uhasselt.be; $\quad$ jens.maggen@uhasselt.be; \\ sara.vanderheyden@uhasselt.be;
}

${ }^{\mathrm{c}}$ Faculty of Chemical Engineering, Universidad de Oriente, Santiago de Cuba, Cuba; falcon@uo.edu.cu;

${ }^{d}$ Department of Polymer and Carbonaceous Material, Faculty of Chemistry, Wroclaw University of Technology, Gdanska 7/9, 50-344 Wroclaw, Poland; grazyna.gryglewicz@pwr.edu.pl;

\begin{abstract}
Activated carbon produced by a traditional two step activation procedure from coffee husks (HAC) and cocoa seed husks (CAC) were used as adsorbents for Ni(II) removal in aqueous solution. Temperature, activation time and added water amount used during the activation process are studied through a model equation designed by a two-level full factorial design. Analysis of variance was used in evaluating AC in multiple response optimization to maximize the yield and adsorption capacity as system responses. The adsorption behaviour of Ni(II) was also evaluated through isotherm models of Langmuir, Freundlich, and Langmuir-Freundlich. For both CAC and HAC, the Langmuir-Freundlich model is slightly superior to the Langmuir and Freundlich models. Mostly CAC adsorbs higher amount of Ni(II) than HAC.
\end{abstract}

Keywords: Adsorption, Ni(II), multiple response optimization, activated carbon, coffee husk, cocoa seed husk

*Corresponding author. Tel: +32(0)11 268320; Fax: +32(0)11 268301.

E-mail address: jan.yperman@uhasselt.be

\section{Introduction}

Environmental pollution is still growing as urbanization and industrialization have been intensified in the last decades [1]. Environmental contaminations, particularly the contamination of surface and groundwater resources have become a considerable ecological concern, due to the presence of harmful materials (dissolved heavy metals and organic pollutants, waste from factories) in waters [2].

Heavy metals are hazardous contaminants, due to their toxicity and strong propensity to accumulate in the environment and in the food chain. The treatment of wastewater contaminated with these metals is a primary concern $[3,4]$.

Activated carbons (ACs) are very effective in treating low metal-ion concentration in aqueous solutions [59]. Due to their high amount of micropores and mesopores, their great surface area [3], the variety of surface functional groups interacting with the heavy metal ions and even the possibility to increase the adsorption capacity by modifying with other functional groups or using additives [3, 10-12], makes these adsorbents interesting candidates in wastewater treatments. The characteristics of the adsorbent significantly affect their adsorption capacity. Generally, the properties of the AC differ depending on the nature of the raw material and the conditions of the activation process [13].

The agro-waste receives a lot of attention as cheap source for the production of AC and makes this alternative more attractive for small-scale industries [14-17]. Agricultural waste for AC production is mainly coming from shells and stones of the fruits. However, waste resulting from the production of rice, coffee, maize, cocoa, sugarcane and corn gets more and more attention [18]. The preparation of ACs from waste materials using pyrolysis offers economic and environmental advantages [19]. This is the main reason why despite the effectiveness of other adsorbents as clays, ion-exchange resins, zeolite and synthetic composites [20-24] the low-cost activated carbons are interesting candidates for heavy metals removal. 
Nickel is one of the major toxic metals. Several industries, such as electroplating, nonferrous metals mineral processing, dyeing and steam-electric power plants have contributed to the contamination of different water bodies with nickel [20]. Mineral processing of this element leaves high levels of nickel ions in aquatic environment [4]. Around 40-45 mg/L is determined in the liquor waste from an acid leaching technology. In addition, the $\mathrm{Ni}(\mathrm{II})$-salts are known to be carcinogenic. According to the World Health Organization (WHO) general "safe" concentration values should be below $0.2 \mathrm{mg} / \mathrm{L}[25,26]$.

In the search of a proper biomass for the production of cost-effective adsorbents for Ni(II) removal, taking into account its price, purity and availability, also the relationship yield-adsorption capacity is of importance. The carbon contents of these products are lower as compared to anthracite or coal. Therefore, the yields of activated carbons from these precursors are estimated to be lower. Nevertheless, its lower cost gives noteworthy more impact than its lower yield. The high content of volatile matters presents in the biomass is ideal to produce a highly porous structure of activated carbons [27].

The purpose of statistically designing of an experiment is to gather the maximum amount of relevant information with a minimum cost of time and resources. The factorial design of experiments, combined with statistical methods of data analysis, offers wider and more distinguished information on the system, while conclusions are of better usability [28]. The aim of the present study is to evaluate the effect of activation temperature, time and water amount (used to produce steam) on yield and adsorption capacity of coffee and cocoa seed husks AC in the adsorption of Ni(II) ions by two-level full factorial design analysis of variance (ANOVA) and multiple response optimization. Also the adsorption characteristics of $\mathrm{Ni}$ (II) are studied by three different adsorption isotherm models: Langmuir, Freundlich and Langmuir-Freundlich.

\section{Materials and Methods}

\subsection{Chemicals}

All reagents used were of analytical grade and purchased from Merck, Sigma-Aldrich NV/SA, Belgium. Metal solution was prepared by dissolving NiSO4.7H2O in Milli-Q water to obtain a Ni stock solution of $5000 \mathrm{mg} / \mathrm{L}$. All other solutions were prepared by diluting this stock solution. The $\mathrm{pH}$ of the solution was adjusted with $0.1 \mathrm{~N} \mathrm{NaOH}$ or $0.1 \mathrm{~N} \mathrm{HCl}$ solution. The concentration of nickel ions was determined using an inductively coupled plasma spectrophotometer employing a Perkin Elmer Optima 3000 DV ICP-AES device with an axial plasma configuration.

\subsection{Raw materials, preparation and production of activated carbon}

Coffee and cocoa seed husks were acquired from the eastern region of Cuba. AC has been prepared from the above materials. Samples are first pyrolyzed in an oxygen-free atmosphere $\left(\mathrm{N}_{2}\right)$ in a lab-scale reactor [29]. For each experiment, a known amount of sample is introduced into the reactor. After the reactor is sealed and placed under a stream of nitrogen $(2 \times 70 \mathrm{~mL} / \mathrm{min})$ the reactor is heated with a rate of $10^{\circ} \mathrm{C} / \mathrm{min}$ to $450^{\circ} \mathrm{C}$ and then held for an isothermal period of 1 hour to complete the pyrolysis process. The sample is continuously kept in motion by an Archimedes screw in order to achieve a uniform heat distribution. The reactor is heated up with a special tailored heating mantle, and the temperature is checked using a thermocouple located inside the reactor [29]. During the thermal treatment, the sample is subjected to a thermal cracking and volatilization. The gases that are formed leave the reactor and passed through of a condensation unit. The condensed fraction is pyrolytic oil. The formed biochar remains behind in the reactor and the non-condensable gases leave the system. The biochar is activated through physical activation by steam in a second step.

For activation, the biochar is introduced in a horizontal quartz reactor and fixed with two quartz wool plugs. The biochar is heated up under a $\mathrm{N}_{2}$ atmosphere to a pre-selected activation temperature with a heating rate of $20^{\circ} \mathrm{C} / \mathrm{min}$. At a fixed activation temperature, the atmosphere is switched from $\mathrm{N}_{2}$ to water vapour to complete the activation process for a given activation time [30].

The yield (\%) of coffee husks activated carbon (HAC) and cocoa seed husks activated carbon (CAC) is calculated based on the following equation:

$Y=\frac{m_{A C}}{m_{0}} \times 100$ 
where $m_{A C}(\mathrm{~g})$ is the dry weight of the activated carbon and $m_{0}(\mathrm{~g})$ is the dry weight of the biochar.

\subsection{Experimental design}

The factorial design is widely used in experiments involving several factors where it is necessary to study the joint effect of the factors on a response. The $2^{k}$ design provides the smallest number of trials with which $k$ factors can be studied in a complete factorial design [31].

The Design Expert Software version 10 was used for the experimental design and data analysis. In this research a three-factor two-level (high and low or +1 and -1 ) full factorial design $\left(2^{3}\right.$ trials) was used. Two responses (the yield and the adsorption capacity average) were simultaneously optimized by studying the factors: the activation temperature, activation time, and added water amount (to produce steam) at the levels shown in Table 1. Analysis of variance (ANOVA) was used to measure the magnitude of effects of factors studied on the system responses.

Table 1 Independent variables and their coded levels for $2^{3}$ factorial design

\begin{tabular}{lcccccc}
\hline & & & \multicolumn{2}{c}{ Range and levels } & \multicolumn{2}{c}{ Coded responses } \\
\cline { 4 - 7 } Independent variables & Code & Units & -1 & +1 & yield (\%) & qexp \\
\hline Temperature & $A$ & ${ }^{\circ} \mathrm{C}$ & 850 & 900 & & \\
Activation time & $B$ & $\min$ & 30 & 45 & $\mathrm{R} 1$ & $\mathrm{R} 2$ \\
Added water amount & $\mathrm{C}$ & $\mathrm{mL}$ & 10 & 15 & & \\
\hline
\end{tabular}

\subsection{Optimization of multiple responses using desirability function}

Desirability function D, which was proposed by Harrington [32], and later optimized by Derringer and Suich in 1980 [33], is an optimization technique for one or multiple responses and it has been used by many researchers [34-38]. The desirability process contains three stages: (1) predicting responses on the dependent variable by fitting the observed responses using an equation based on the levels of the independent variables, (2) finding the levels of the independent variables that simultaneously produce the most desirable predicted responses on the dependent variables and (3) maximize the overall desirability with respect to the controllable variables [39].

In order to combine the multiple responses in a single function that can be maximized, a desirability function is defined first for each answer $d_{i}\left(\hat{y}_{i}\right)$. The desirability function $d_{i}\left(\hat{y}_{i}\right)$ shows the desirability value on a scale of 0 to 1 (lowest desirability to highest desirability) [35]. When the $n$ variables are converted in desirability functions, they are combined into an overall desirability function known as Global Desirability (D), using the following equation [40]:

$D=\left(d_{1}^{r_{1}} \times d_{2}^{r_{2}} \times \ldots \ldots \times d_{n}^{r_{n}}\right)^{\frac{1}{\sum r_{i}}}$

where the $r_{i}$ is the relative importance among the $n$ variables and responses with target $i=1,2, ., n$.

Desirability function $\mathrm{d}_{\mathrm{i}}\left(\hat{\mathrm{y}}_{\mathrm{i}}\right)$ takes some of the three ways, depending if the answer should be maximized, minimized or to reach an objective value, within a suitable range of response value settings by $\left(\mathrm{U}_{\mathrm{i}}-\mathrm{L}_{\mathrm{i}}\right)$. Where $U_{i}$ is the upper acceptable value for the response and $\mathrm{L}_{\mathrm{i}}$ is the lower. In addition, if the response has to be maximized, $\mathrm{d}_{\mathrm{i}}\left(\hat{\mathrm{y}}_{\mathrm{i}}\right)$ is described by the following equation [40]:

$d_{i}\left(\hat{\mathrm{y}}_{i}(x)\right)=\left[\begin{array}{cc}0 & \text { if } \hat{\mathrm{y}}_{i}(x)<L_{i} \\ \left(\frac{\hat{\mathrm{y}}_{i}(x)-L_{i}}{U_{i}-L_{i}}\right)^{s} & \text { if } L_{i} \leq \hat{\mathrm{y}}_{i}(x) \leq U_{i} \\ 1 & \text { if } \hat{\mathrm{y}}_{i}(x)>U_{i}\end{array}\right]$

where $s$ defines the shape of the function and is a power value named "weight", established by the analyst to determine how significant it is for $\hat{y}_{i}$ to be close to the maximum. The equation for minimizing $d_{i}\left(\hat{y}_{i}\right)$ is [40]: 
$d_{i}\left(\hat{\mathrm{y}}_{i}(x)\right)=\left[\begin{array}{cc}1 & \text { if } \hat{\mathrm{y}}_{i}(x)<L_{i} \\ \left(\frac{U_{i}-\hat{\mathrm{y}}_{i}(x)}{U_{i}-L_{i}}\right)^{t} & \text { if } L_{i} \leq \hat{\mathrm{y}}_{i}(x) \leq U_{i} \\ 0 & \text { if } \hat{\mathrm{y}}_{i}(x)>U_{i}\end{array}\right]$

where $t$ is the weight to determine how significant is it for $\hat{y}_{i}$ to be close to the minimum. When a target value $T_{i}$ is the best desirable response, the function setting is [40]:

$$
d_{i}\left(\hat{\mathrm{y}}_{i}(x)\right)=\left[\begin{array}{cc}
0 & \text { if } \hat{\mathrm{y}}_{i}(x)<L_{i} \\
\left(\frac{\hat{\mathrm{y}}_{i}(x)-L_{i}}{T_{i}-L_{i}}\right)^{s} & \text { if } L_{i} \leq \hat{\mathrm{y}}_{i}(x) \leq T_{i} \\
1 & \hat{\mathrm{y}}_{i}(x)=T_{i} \\
\left(\frac{\hat{\mathrm{y}}_{i}(x)-U_{i}}{T_{i}-U_{i}}\right)^{t} & \text { if } T_{i} \leq \hat{\mathrm{y}}_{i}(x) \leq U_{i} \\
0 & \text { if } \hat{\mathrm{y}}_{i}(x)>U_{i}
\end{array}\right]
$$

\subsection{Adsorption isotherms}

Adsorption isotherm tests are performed using $25 \mathrm{mg}$ of adsorbent dose and $50 \mathrm{~mL}$ of $\mathrm{Ni}(\mathrm{II})$ solution (10, 20, 30, 40 and $50 \mathrm{mg} / \mathrm{L}$ ) in an Erlenmeyer flask of $250 \mathrm{~mL}$. The experiments are carried out at $25 \pm 1^{\circ} \mathrm{C}$, solution $\mathrm{pH}$ of 6 and shake speed $50 \mathrm{rpm}$, for $24 \mathrm{~h}$, based on a previous study [41]. After each experiment, the solution is filtered and the concentration of $\mathrm{Ni}(\mathrm{II})$ is determined.

The amount of $\mathrm{Ni}(\mathrm{II})$ adsorbed $\mathrm{q}_{\mathrm{e}}(\mathrm{mg} / \mathrm{g})$ at equilibrium, is calculated using the following equation:

$q_{e}=\frac{C_{0}-C_{e}}{m} \times V$

where $\mathrm{C}_{0}$ and $\mathrm{C}_{\mathrm{e}}$ are the initial and equilibrium concentration of $\mathrm{Ni}(\mathrm{II})$ respectively $(\mathrm{mg} / \mathrm{L}), \mathrm{V}$ is the volume of the solution (L) and $m$ is the weight of the adsorbent used (g). The average of adsorption capacity ( $\mathrm{q}_{\mathrm{e}}$ ) determined is used as system response (Table 1).

Freundlich, Langmuir and Langmuir-Freundlich models are fitted to adsorption isotherm data for equilibrium description. Freundlich isotherm is an empirical model and is based on a multilayer adsorption, with non-uniform distribution of adsorption, heat and affinities over the heterogeneous surface [42, 43] and in linear form it is given by:

$\log q_{e}=\log K_{F}+\frac{1}{n} \log c_{e}$

where $\mathrm{K}_{\mathrm{F}}$ is related with the adsorption capacity and $n$ is related to the adsorption intensity [42].

Langmuir isotherm is based on a theoretical model and assumes a monolayer adsorption over an energetically homogeneous adsorbent surface containing a finite number of adsorption sites. It does not take into account interactions between adsorbed molecules [44, 45]. It can be represented by the following linear equation:

$\frac{1}{q_{e}}=\frac{1}{q_{m}}+\left(\frac{1}{K_{L} q_{m}}\right) \frac{1}{c_{e}}$

where $\mathrm{q}_{\mathrm{m}}$ and $\mathrm{K}_{\mathrm{L}}$ are constants related to the maximum adsorption capacity (mg/g) and the adsorption energy (L/mg), respectively [46, 47].

The Langmuir-Freundlich isotherm equation [48] represents the combination of Langmuir and Freundlich behaviour through:

$q_{e}=\frac{q_{m_{L F}}\left(K_{L F} c_{e}\right)^{n_{L F}}}{\left(K_{L F} c_{e}\right)^{n_{L F+1}}}$

where $\mathrm{q}_{\mathrm{mLF}}, \mathrm{K}_{\mathrm{LF}}$ and $n_{\mathrm{LF}}$ are the maximum adsorption capacity (mg/g), the adsorption energy $(\mathrm{L} / \mathrm{mg})$ and the adsorption intensity for Langmuir-Freundlich model. To determine the parameters of the model nonlinear curve fitting was applied to the data using the Origen81. Origen 8.1 program. 


\subsection{Characterization of the adsorbents prepared at optimal conditions}

Porous texture analysis has been carried out by $\mathrm{N}_{2}$ and $\mathrm{CO}_{2}$ adsorption at $-196{ }^{\circ} \mathrm{C}$ and $0{ }^{\circ} \mathrm{C}$, respectively, in an Autosorb iQ apparatus (Quantachrome Instruments). The samples were outgassed overnight at $300{ }^{\circ} \mathrm{C}$ before $\mathrm{N}_{2}$ adsorption and for $5 \mathrm{~h}$ at $300{ }^{\circ} \mathrm{C}$ before $\mathrm{CO}_{2}$ adsorption under high vacuum. The specific surface area ( $\mathrm{S}_{\mathrm{BET}}$ ) was calculated from the $\mathrm{N}_{2}$ sorption isotherm data using the BET (Brunauer, Emmett and Teller) method. The amount of nitrogen adsorbed at the relative pressure of $\mathrm{p} / \mathrm{p}_{0}=0.96$ was used to determine the total pore volume $\left(\mathrm{V}_{\mathrm{T}}\right)$. The $\mathrm{N}_{2}$ isotherms in the $\mathrm{p} / \mathrm{p}_{0}$ range from 0.0005 to 0.96 reflect the adsorption that takes place in the mesopores (pores with a width of 2-50 nm) and in the micropores larger than $0.7 \mathrm{~nm}$. The micropore volume $\left(\mathrm{V}_{\mathrm{DR}, \mathrm{N} 2}\right)$ and the average micropore size $\left(\mathrm{L}_{0, \mathrm{~N} 2}\right)$ were estimated by applying the DubininRadushkevich and Stoeckli equations, respectively, to data collected at low pressures $\left(\mathrm{p} / \mathrm{p}_{0}<0.015\right)$ [49]. The $\mathrm{V}_{\mathrm{DR}, \mathrm{N} 2} / \mathrm{V}_{\mathrm{T}}$ ratio was used to assess the contribution of the micropores to the total pore volume. The Quenched-Solid Density Functional Theory (QSDFT) analysis [50] was applied to the $\mathrm{N}_{2}$ adsorption isotherms to determine pore size distribution (PSD).

The $\mathrm{CO}_{2}$ isotherms at $0{ }^{\circ} \mathrm{C}$ and low relative pressure $\mathrm{p} / \mathrm{p}_{0}<0.1$ are assumed to correspond to the adsorption taking place in the narrow micropores in the range of 0.4-0.8 nm (ultramicropores). These isotherm data are used to calculate the ultramicropore volume $\left(\mathrm{V}_{\mathrm{DR}, \mathrm{CO} 2}\right)$ and ultramicropore size $\left(\mathrm{L}_{0, \mathrm{CO} 2}\right)$ by means of the Dubinin-Radushkevich and Stoeckli equations, respectively [49]. Assuming the presence of slit-shaped ultramicropores, the surface of their walls was determined from the following equation: $\mathrm{S}_{\mathrm{CO} 2}\left(\mathrm{~m}^{2} / \mathrm{g}\right)=2000$ $\mathrm{V}_{\mathrm{DR}, \mathrm{CO} 2} / \mathrm{L}_{0, \mathrm{CO} 2}$ [51]. The PSD is also calculated from the $\mathrm{CO}_{2}$ isotherm data by applying the Non-Local Density Functional Theory (NLDFT) [52] in order to characterize ultramicropores.

Elemental analysis of carbon (C), nitrogen (N), hydrogen (H), sulphur (S) and oxygen (O) (by difference) is carried out with a Thermo Electron Flash EA1113 element analyser with BBOT (2,5-bis(5-tert-butylbenzoxazol-2-yl)thiophene with formula $\mathrm{C}_{26} \mathrm{H}_{26} \mathrm{~N}_{2} \mathrm{O}_{2} \mathrm{~S}$ ) as standard for calibration. ATR-FTR measurements are carried out with a Bruker Vertex 70 equipped with a DTGS detector. The dried samples are directly measured in the wavenumber range from 4000 to $600 \mathrm{~cm}^{-1}$ at a resolution of $4 \mathrm{~cm}^{-1}$ using a PIKE accessory.

\section{Results and discussion}

\subsection{Designing of experiments and statistical model assessment}

Tables 2-3 show the experimental results based on $2^{3}$ full factorial design for HAC and CAC. The 16 runs represent the possible combination of coded factors in a random way with one replicate. The observed and predicted responses for ACs adsorption capacity and yield for HAC and CAC at the same experimental conditions are given in tables 2 and 3, respectively.

Table 2 Experimental design based on $2^{3}$ full factorial design with one replicate for HAC

\begin{tabular}{|c|c|c|c|c|c|c|c|c|c|}
\hline \multirow{3}{*}{$\begin{array}{l}\text { Run } \\
\text { no. }\end{array}$} & \multicolumn{3}{|c|}{ Independent variables (coded) } & \multicolumn{6}{|c|}{ Responses } \\
\hline & & & & \multicolumn{3}{|c|}{ R1(yield \%) } & \multicolumn{3}{|c|}{$\mathrm{R} 2$ ( $\left.\mathrm{q}_{\mathrm{e}} \mathrm{mg} / \mathrm{g}\right)$} \\
\hline & A & $B$ & C & Observed & Predicted & Residual & Observed & Predicted & Residual \\
\hline 1 & -1 & 1 & -1 & 49.44 & 49.19 & 0.25 & 51.13 & 51.34 & -0.21 \\
\hline 2 & -1 & -1 & -1 & 53.98 & 53.28 & 0.70 & 50.55 & 50.55 & 0.00 \\
\hline $3^{(*, 1)}$ & -1 & 1 & -1 & 48.95 & 49.19 & -0.24 & 51.56 & 51.34 & 0.22 \\
\hline 4 & 1 & 1 & -1 & 37.28 & 37.66 & -0.38 & 50.95 & 51.27 & -0.32 \\
\hline 5 & 1 & -1 & 1 & 34.28 & 34.91 & -0.63 & 50.39 & 50.22 & 0.17 \\
\hline 6 & 1 & 1 & 1 & 28.39 & 28.30 & 0.01 & 51.11 & 51.13 & -0.02 \\
\hline 7 & -1 & -1 & 1 & 55.93 & 55.05 & 0.88 & 49.00 & 48.82 & 0.18 \\
\hline 8 & 1 & -1 & -1 & 42.76 & 42.50 & 0.26 & 50.55 & 50.55 & 0.00 \\
\hline $9^{(*, 4)}$ & 1 & 1 & -1 & 38.04 & 37.66 & 0.38 & 51.60 & 51.27 & 0.33 \\
\hline 10 & -1 & 1 & 1 & 43.18 & 42.43 & 0.75 & 50.27 & 50.28 & -0.01 \\
\hline $11^{(*, 6)}$ & 1 & 1 & 1 & 28.20 & 28.30 & -0.01 & 51.16 & 51.13 & 0.02 \\
\hline 12 & -1 & 1 & 1 & 41.67 & 42.43 & -0.76 & 50.28 & 50.28 & 0.01 \\
\hline $13^{(*, 8)}$ & 1 & -1 & -1 & 42.24 & 42.50 & -0.26 & 50.55 & 50.55 & 0.00 \\
\hline $14^{(*, 7)}$ & -1 & -1 & 1 & 54.17 & 55.05 & -0.88 & 48.64 & 48.82 & -0.18 \\
\hline $15^{(*, 5)}$ & 1 & -1 & 1 & 35.53 & 34.91 & 0.63 & 50.05 & 50.22 & -0.17 \\
\hline $16^{(*, 2)}$ & -1 & -1 & -1 & 52.58 & 53.28 & -0.70 & 50.55 & 50.55 & 0.00 \\
\hline
\end{tabular}


The effect of the factors (independent variables) and their interactions on both responses can be represented for an empirical relationship expressed by a lineal equation. The coded mathematical models obtained from $2^{3}$ full factorial experimental design model and the input variables for both adsorbents are expressed by Eqs. (10-13):

$R 1_{H A C}=42.91-7.07 A-3.52 B-2.74 C+0.66 A B-1.50 A C-1.29 B C+0.85 A B C$

Predicted $R^{2}=0.9958$ and adjusted $R^{2}=0.9922$

$R 2_{H A C}=50.52+0.27 A+0.49 B-0.41 C-0.076 A B+0.29 A C+0.11 B C-0.059 A B C$

Predicted $R^{2}=0.9562$ and adjusted $R^{2}=0.9179$

Table 3 Experimental design based on $2^{3}$ full factorial design with one replicate for CAC

\begin{tabular}{|c|c|c|c|c|c|c|c|c|c|}
\hline \multirow{3}{*}{$\begin{array}{l}\text { Run } \\
\text { no. }\end{array}$} & \multicolumn{3}{|c|}{ Independent variables (coded) } & \multicolumn{6}{|c|}{ Responses } \\
\hline & & & & \multicolumn{3}{|c|}{ R1 (yield \%) } & \multicolumn{3}{|c|}{ R2 (qe mg/g) } \\
\hline & $A$ & $B$ & C & Observed & Predicted & Residual & Observed & Predicted & Residual \\
\hline 1 & 1 & 1 & -1 & 41.89 & 41.46 & 0.43 & 57.71 & 57.34 & 0.37 \\
\hline $2^{(*, 1)}$ & 1 & 1 & -1 & 41.03 & 41.46 & -0.43 & 56.97 & 57.34 & -0.37 \\
\hline 3 & 1 & 1 & 1 & 40.10 & 39.66 & 0.44 & 58.82 & 58.88 & -0.06 \\
\hline 4 & 1 & -1 & -1 & 53.72 & 54.27 & -0.55 & 51.81 & 52.20 & -0.39 \\
\hline 5 & -1 & -1 & -1 & 66.12 & 66.05 & 0.07 & 50.00 & 50.21 & -0.21 \\
\hline $6^{(*, 5)}$ & -1 & -1 & -1 & 65.98 & 66.05 & -0.07 & 50.42 & 50.21 & 0.21 \\
\hline 7 & -1 & -1 & 1 & 52.28 & 53.34 & -1.06 & 53.37 & 53.13 & 0.24 \\
\hline 8 & -1 & 1 & 1 & 47.60 & 47.00 & 0.60 & 57.54 & 57.27 & 0.27 \\
\hline $9^{(*, 7)}$ & -1 & -1 & 1 & 54.40 & 53.34 & 1.06 & 52.89 & 53.13 & -0.24 \\
\hline $10^{(*, 8)}$ & -1 & 1 & 1 & 46.39 & 47.00 & -0.61 & 57.01 & 57.27 & -0.26 \\
\hline $11^{(*, 4)}$ & 1 & -1 & -1 & 54.83 & 54.27 & 0.56 & 52.60 & 52.20 & 0.40 \\
\hline 12 & -1 & 1 & -1 & 53.48 & 53.78 & -0.30 & 55.35 & 55.55 & -0.20 \\
\hline $13^{(*, 12)}$ & -1 & 1 & -1 & 54.07 & 53.78 & 0.29 & 55.75 & 55.55 & 0.20 \\
\hline $14^{(*, 3)}$ & 1 & 1 & 1 & 39.23 & 39.66 & -0.43 & 58.95 & 58.88 & 0.06 \\
\hline 15 & 1 & -1 & 1 & 43.49 & 44.33 & -0.84 & 57.17 & 57.09 & 0.08 \\
\hline $16^{(*, 15)}$ & 1 & -1 & 1 & 45.16 & 44.33 & 0.83 & 57.02 & 57.09 & -0.08 \\
\hline
\end{tabular}

${ }^{(*, \#)}$ replicate of the run $\#$, i.e $(*, 1)$ replicate of the run 1

$R 1_{C A C}=49.99-5.05 A-4.51 B-3.90 C+0.14 A B+0.97 A C+1.76 B C+0.28 A B C$

Predicted $R^{2}=0.9944$ and adjusted $R^{2}=0.9894$

$R 2_{C A C}=55.21+1.17 A+2.05 B+1.38 C-0.32 A B+0.22 A C-0.57 B C-0.27 A B C$

Predicted $R^{2}=0.9921$ and adjusted $R^{2}=0.9851$

The correlation coefficient $R^{2}$ is a measure of the quality of the developed models for predicting a response value. The difference in adjusted $R^{2}$ (a measure of the amount of variation on the mean explained by the model) and predicted $R^{2}$ (a measure of the variation in data explained by the model) should be approximately 0.20 of each other. In the study all the predicted $R^{2}$ are in reasonable agreement with adjusted $R^{2}$. The models can be used to navigate the design space.

The normality of the data is checked by plotting a normal probability versus externally studentized residuals (Fig.1). As the data points on the plot are approximate to a straight line, the data are normally distributed. Negative signs in equations (10-13) show antagonistic effects, while positive signs show synergistic effects. Fig. 2 illustrates the perturbation in the system responses with the change in the levels of the coded factors from a reference point. For the yield \% (R1) the increment in the factors studied have a negative effect for both adsorbents, whereas for adsorption capacity (R2) the increase of the factors $A$ (temperature) and $B$ (time of activation) have a positive effect. The influence of $C$ (water amount) depends on the raw material used for the production of ACs. Its raise has a negative consequence for the adsorption capacity of HAC and the opposite for CAC.

The effect of activation temperature and time on system responses can be explained as follows: as activation temperature and time increase, the development of new pores as a result of volatile matter released and the widening of existing ones enable the increment of adsorption capacity up to the optimal conditions. Nevertheless, this causes a decrease in the yield. The increment of added water amount (as steam) produces the opening of new pores into the carbon structure, but higher flows damage/destroy more severe AC structure/matrix. 


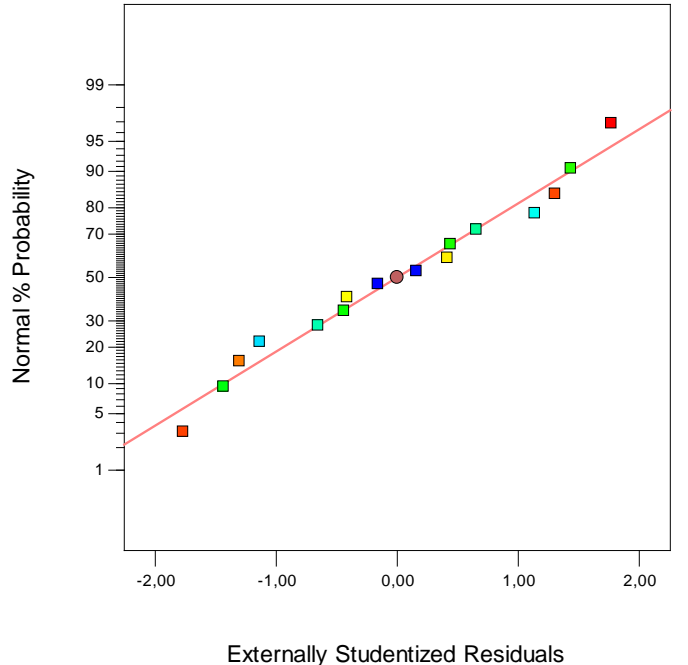

a)

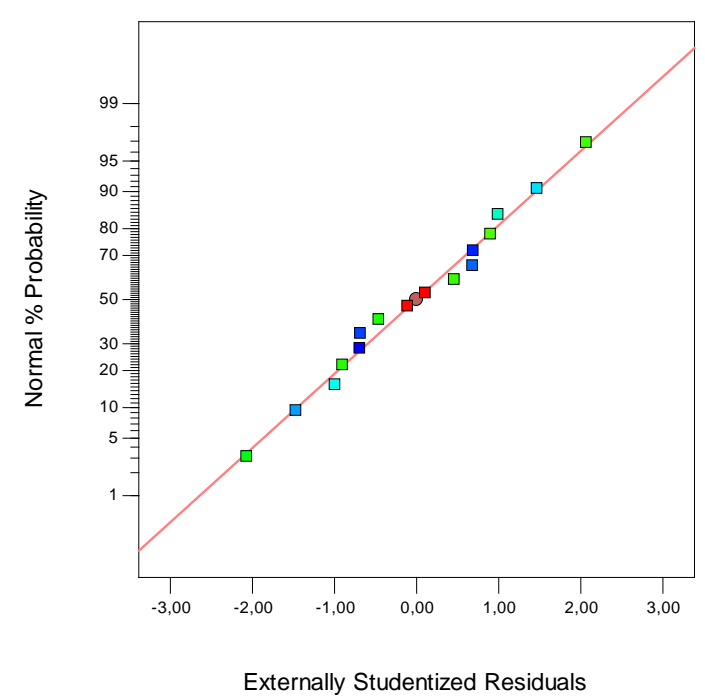

c)

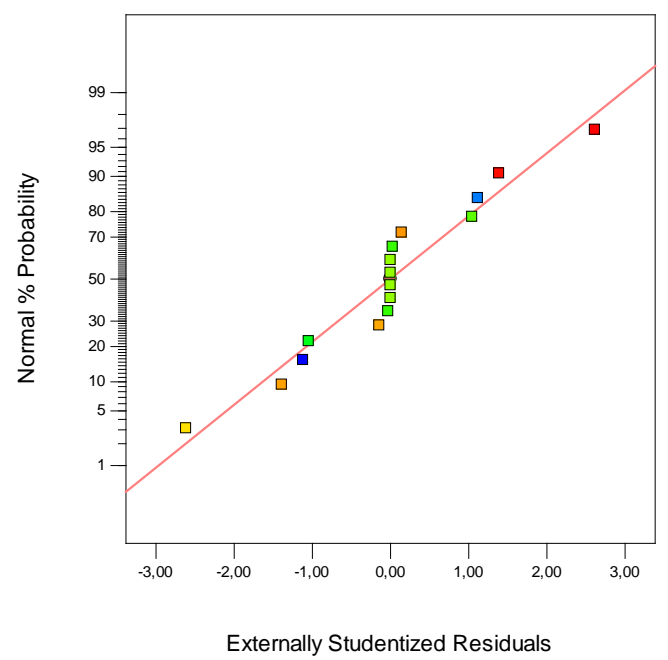

b)

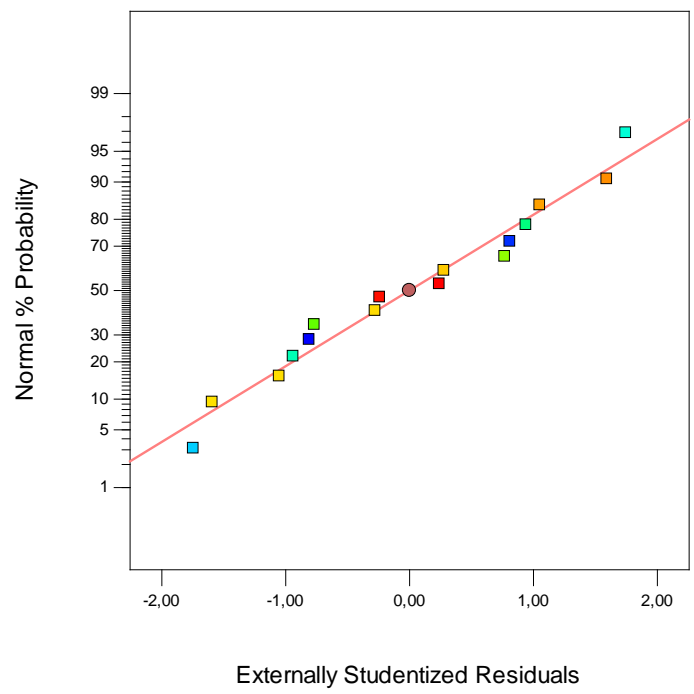

d)

Fig. 1 Normal \% probability versus externally studentized residual: a) R1 of HAC, b) R2 of HAC, c) R1 of CAC, d) R2 of CAC. 


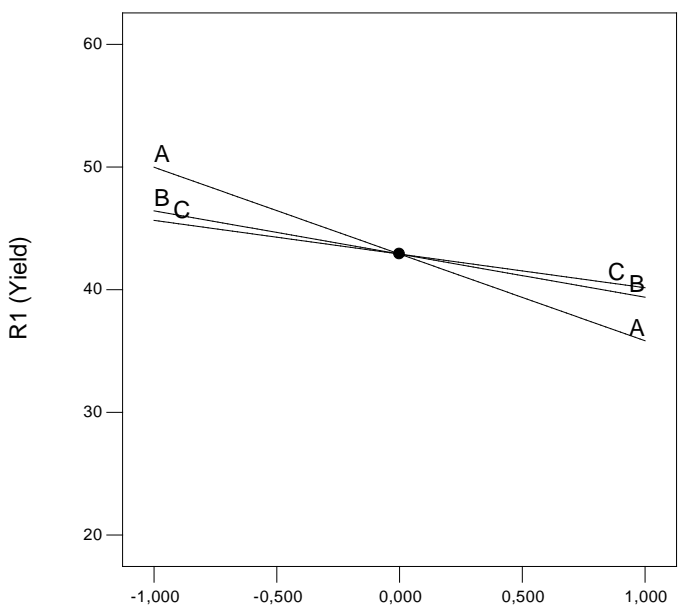

a)

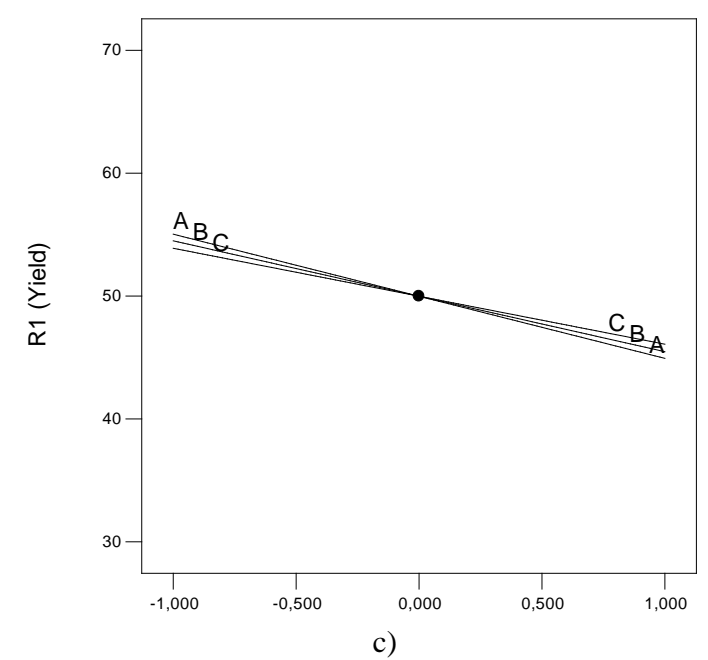

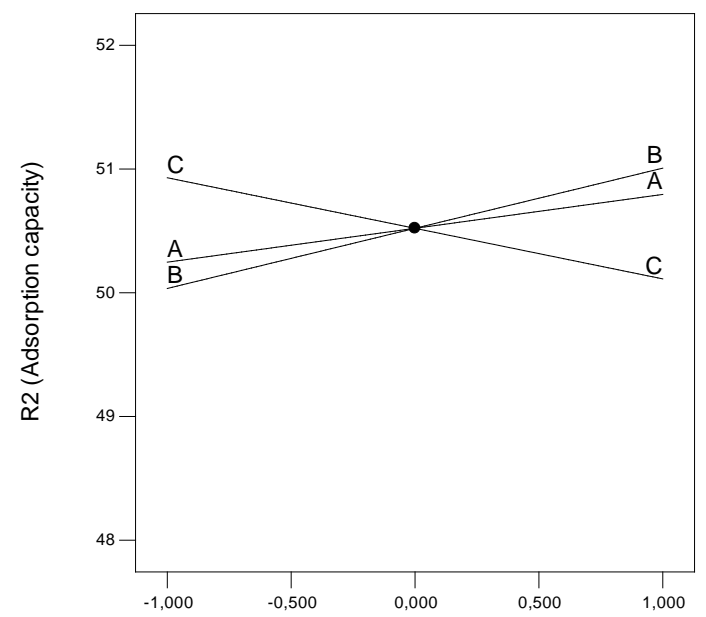

b)

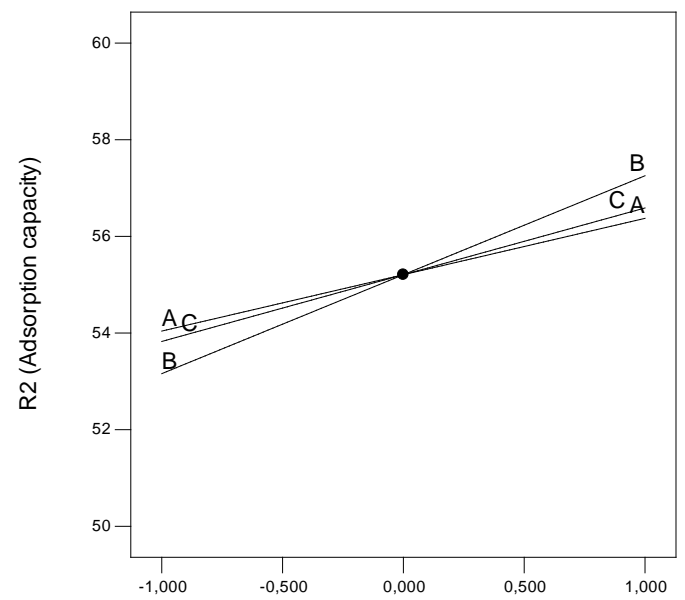

d)

Fig. 2 Perturbation on the system responses by the change of the levels of the factors A, B and C: a) and b) HAC, c) and d) CAC.

The significance of the model effects and their interactions in the system responses were studied using analysis of variance (ANOVA). ANOVA is a statistical technique that subdivides the total variation of data into modules related with definite sources of variation, with the objective of testing hypotheses on the parameters of the model [34]. The Sum of Squares (SS) quantifies its importance in the process and Pvalues $<0.05$ indicate that model terms are significant. As Table 4 shows, the main effects and their interactions have larger impact on R1 than on R2 for both adsorbents. The models, the main effects and their interactions are significant, except for $A B$ and $A B C$ effects for $\mathrm{R} 1_{C A C}$ and $\mathrm{R} 2_{H A C}$. Among all significant variables the temperature $(A)$ has the largest effect on R1 response for HAC and CAC (Fig. 2a, 2c). While for R2 response the activation time $(B)$ has the major effect for both ACs (Fig. 2b, 2d). After neglecting insignificant terms, the resultant models $\mathrm{R} 2_{H A C}$ and $\mathrm{R} 1_{C A C}$ can be expressed as (based on Table 4):

$$
\begin{aligned}
& R 2_{H A C}=50.52+0.27 A+0.49 B-0.41 C+0.29 A C+0.11 B C \\
& R 1_{C A C}=49.99-5.05 A-4.51 B-3.90 C+0.97 A C+1.76 B C
\end{aligned}
$$

For R1 HAC equation (10) and for R2 $2_{\text {CAC }}$ equation (13) still hold. 
Table 4 Analysis of variance, (ANOVA) results

\begin{tabular}{|c|c|c|c|c|c|c|c|c|c|}
\hline \multirow[b]{2}{*}{ Adsorbent } & \multirow[b]{2}{*}{ Source } & \multicolumn{4}{|c|}{ R1 (\%) } & \multicolumn{4}{|c|}{ R2 (mg/g) } \\
\hline & & $\begin{array}{l}\text { Sum of } \\
\text { Squares }\end{array}$ & $\begin{array}{l}\text { Standard } \\
\text { error }\end{array}$ & F-value & $\mathrm{P}$-value & $\begin{array}{l}\text { Sum of } \\
\text { Squares }\end{array}$ & $\begin{array}{l}\text { Standard } \\
\text { error }\end{array}$ & F-value & P-value \\
\hline \multirow{8}{*}{ HAC } & model & 1200.12 & 0.20 & 273.65 & $<0.0001$ & 9.34 & 0.058 & 24.97 & $<0.0001$ \\
\hline & A & 800.61 & 0.20 & 1277.85 & $<0.0001$ & 1.20 & 0.058 & 22.43 & 0.0015 \\
\hline & B & 198.25 & 0.20 & 316.42 & $<0.0001$ & 3.78 & 0.058 & 70.78 & $<0.0001$ \\
\hline & C & 120.56 & 0.20 & 192.43 & $<0.0001$ & 2.67 & 0.058 & 50.01 & 0.0001 \\
\hline & $A B$ & 6.92 & 0.20 & 11.04 & 0.0105 & 0.093 & 0.058 & 1.74 & 0.2236 \\
\hline & $A C$ & 35.76 & 0.20 & 57.08 & $<0.0001$ & 1.36 & 0.058 & 25.39 & 0.0010 \\
\hline & $B C$ & 26.57 & 0.20 & 42.41 & 0.0002 & 0.18 & 0.058 & 3.38 & 0.1033 \\
\hline & $A B C$ & 11.46 & 0.20 & 18.29 & 0.0027 & 0.055 & 0.058 & 1.03 & 0.3392 \\
\hline \multirow{8}{*}{ CAC } & model & 1044.52 & 0.22 & 201.58 & $<0.0001$ & 128.66 & 0.090 & 142.84 & $<0.0001$ \\
\hline & $A$ & 408.75 & 0.22 & 552.19 & $<0.0001$ & 21.90 & 0.090 & 170.21 & $<0.0001$ \\
\hline & $B$ & 325.71 & 0.22 & 440.01 & $<0.0001$ & 67.32 & 0.090 & 523.19 & $<0.0001$ \\
\hline & C & 243.91 & 0.22 & 329.50 & $<0.0001$ & 30.69 & 0.090 & 238.52 & $<0.0001$ \\
\hline & $A B$ & 0.33 & 0.22 & 0.44 & 0.5245 & 1.64 & 0.090 & 12.73 & 0.0073 \\
\hline & $A C$ & 15.00 & 0.22 & 20.26 & 0.0020 & 0.80 & 0.090 & 6.23 & 0.0372 \\
\hline & $B C$ & 49.60 & 0.22 & 67.00 & $<0.0001$ & 5.15 & 0.090 & 40.05 & 0.0002 \\
\hline & $A B C$ & 1.24 & 0.22 & 1.67 & 0.2321 & 1.16 & 0.090 & 8.98 & 0.0172 \\
\hline
\end{tabular}

\subsection{Desirability function for multiple response optimization}

Optimization of system responses (yield and adsorption capacity) is carried out by a multiple response optimization or a Global Desirability function (D). The optimal operation conditions as activation temperature, time and water amount are settled in the range studied to maximize the yield (R1) and the adsorption capacity (R2). The weight for both responses is fixed to 1. The Design Expert Software version 10 allows to vary the importance of system responses between 5 and 1 (maximum and minimum values). However main effects have larger impact on R1 than R2 and when R2 importance rise from 1 to 5 at fixed importance of R1 equal to 5, the adsorption capacity (R2) increases but the yield (R1) decreases. The R1 values decrease more sharply when R2 importance is fixed among 3-5 (Supplementary material). For the present study the importance of system responses was fixed to 5 and 2 for R1 and R2, respectively.

For HAC, the best desirability value is 0.821 at predicted system responses of R1: 53.11 and R2: 50.58. The operation conditions are temperature $850{ }^{\circ} \mathrm{C}$, activation time $30.5 \mathrm{~min}$ and water amount $10 \mathrm{~mL}$ (fig. $3 \mathrm{a}$ and $3 \mathrm{~b}$ ). While for CAC, the best desirability value is 0.603 with predicted system responses of R1: 58.72 and R2: 53.40 at temperature $850{ }^{\circ} \mathrm{C}$, activation time 39.0 min and water amount $10 \mathrm{~mL}$ (fig. $3 \mathrm{c}$ and 3d). Fig. 3 shows the graphical desirability for both adsorbents.

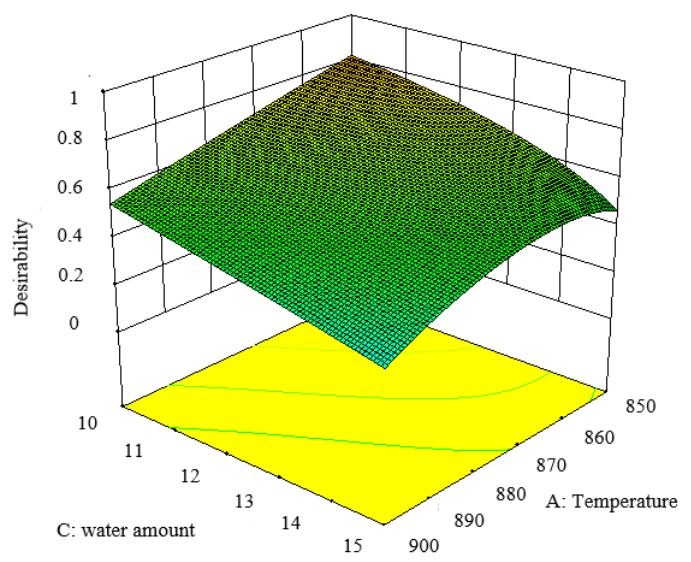

a)

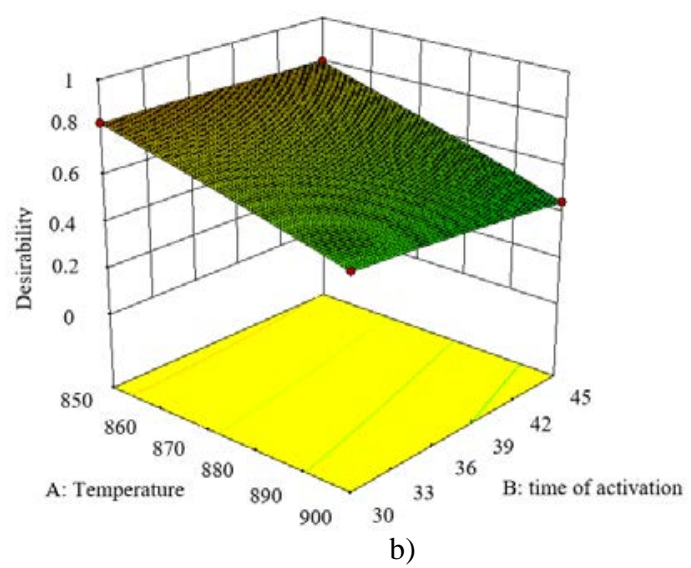

b) 


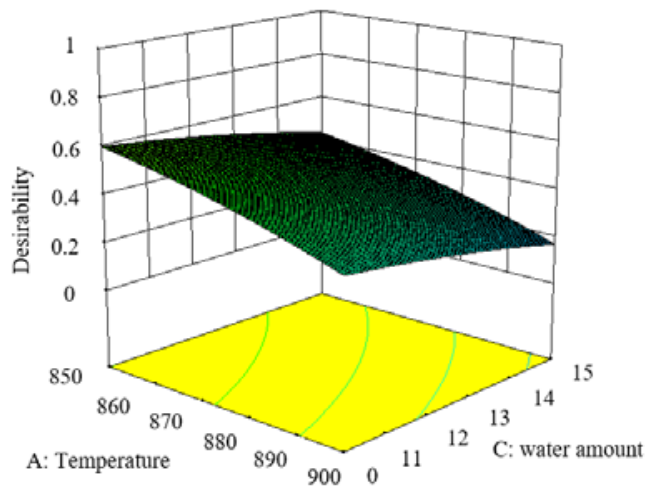

c)

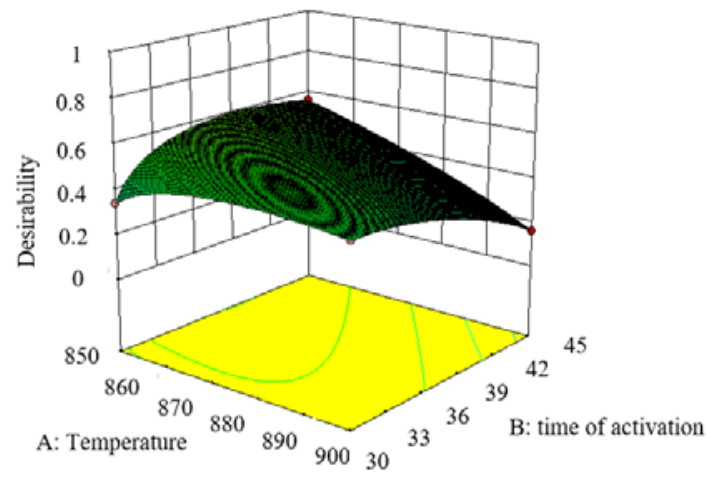

d)

Fig. 3 Desirability 3D response surface plot: a) The effect of temperature and water amount for HAC desirability at fixed activation time of $30.5 \mathrm{~min}, \mathrm{~b}$ ) The effect of temperature and activation time for HAC desirability at fixed water amount of $10 \mathrm{~mL}, \mathrm{c}$ ) The effect of temperature and water amount for CAC desirability at fixed activation time of 39.0 min, d) The effect of temperature and activation time for CAC desirability at fixed water amount of $10 \mathrm{~mL}$.

\subsection{Isotherm studies}

Adsorption equilibrium tests are crucial to assess adsorption behaviour and develop mathematic equations for design purposes. In Fig. 4 the adsorption isotherms are presented for the ACs prepared at the optimal experimental conditions. The adsorption models of Langmuir, Freundlich and Langmuir-Freundlich (Table 5) are adjusted to equilibrium data. The Langmuir-Freundlich model showed a better fit for both ACs, followed by the Langmuir model. Maximum adsorption capacities $\mathrm{q}_{\mathrm{mLF}}$ are clearly higher for CAC than for HAC which is in agreement with multiple response optimization results: predicted system response R2 (adsorption capacity) is greater for CAC than for HAC.

Table 5 Adsorption isotherms parameters (25 mg of AC, $50 \mathrm{~mL}$ of Ni(II): Co $=10-50 \mathrm{mg} / \mathrm{L}, \mathrm{T}=25 \pm 1{ }^{\circ} \mathrm{C}$ )

\begin{tabular}{|c|c|c|c|c|c|c|c|c|c|c|c|}
\hline \multirow[b]{2}{*}{$\begin{array}{l}\text { Conditions } \\
\text { (uncoded } \\
\text { variables) }\end{array}$} & \multirow[b]{2}{*}{ Adsorbent } & \multicolumn{3}{|c|}{ Langmuir model } & \multicolumn{3}{|c|}{ Freundlich model } & \multicolumn{4}{|c|}{ Langmuir-Freundlich model } \\
\hline & & $\begin{array}{c}\mathrm{qm}_{\mathrm{m}} \\
(\mathrm{mg} / \mathrm{g})\end{array}$ & $\begin{array}{c}\mathrm{K}_{\mathrm{L}} \\
(\mathrm{L} / \mathrm{mg})\end{array}$ & $R^{2}$ & $\mathrm{~K}_{\mathrm{F}}$ & $n$ & $R^{2}$ & $\begin{array}{c}\mathrm{q} \mathrm{mLF} \\
(\mathrm{mg} / \mathrm{g})\end{array}$ & $\begin{array}{c}\mathrm{K}_{\mathrm{LF}} \\
(\mathrm{L} / \mathrm{mg})\end{array}$ & $n_{\mathrm{LF}}$ & $R^{2}$ \\
\hline $\begin{array}{l}A: 850^{\circ} \mathrm{C} \\
B: 30 \mathrm{~min} \\
C: 10 \mathrm{~mL}\end{array}$ & HAC & 102.72 & 0.2918 & 0.9692 & 27.17 & 2.20 & 0.9221 & 81.33 & 0.4632 & 1.63 & 0.9870 \\
\hline $\begin{array}{l}A: 850^{\circ} \mathrm{C} \\
B: 39 \mathrm{~min} \\
C: 10 \mathrm{~mL}\end{array}$ & CAC & 104.99 & 0.4547 & 0.9912 & 34.95 & 2.33 & 0.9623 & 110.15 & 0.4061 & 0.93 & 0.9916 \\
\hline
\end{tabular}

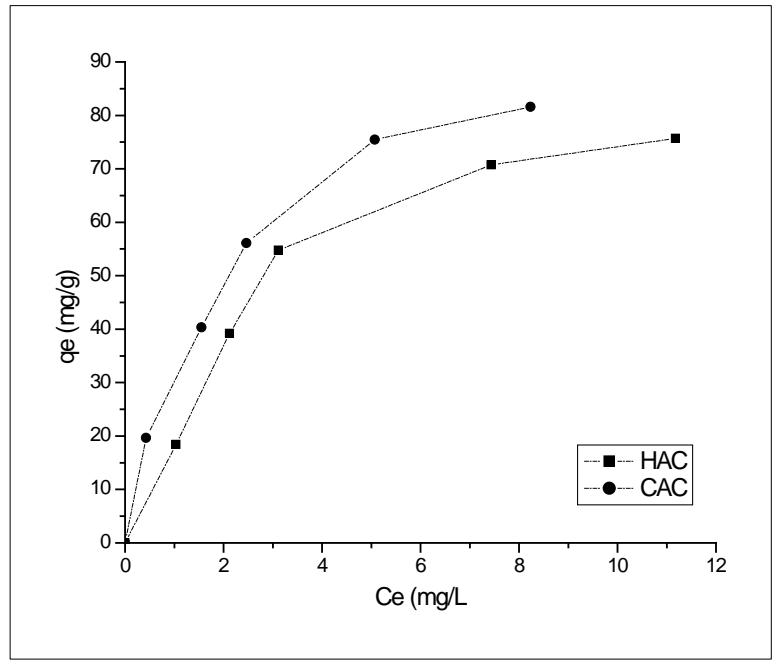


Fig. 4 Adsorption isotherms for CAC and HAC $\left(\mathrm{C}_{0}=10-50 \mathrm{mg} / \mathrm{L}, \mathrm{m}=25 \mathrm{mg}, \mathrm{V}=50 \mathrm{~mL}, \mathrm{pH}=6, \mathrm{~T}=25 \pm 1^{\circ} \mathrm{C}\right.$, shake speed $50 \mathrm{rpm}, \mathrm{t}=24 \mathrm{~h}$ ).

\subsection{Characterization of the adsorbent materials}

Fig. 5a depicts the nitrogen adsorption-desorption isotherms at $-196{ }^{\circ} \mathrm{C}$ for the samples prepared at the optimal experimental conditions. For CAC the isotherm shape shows a sharply increase at low relative pressure of $\mathrm{p} / \mathrm{p}_{0}$ and reaches a plateau in a broad range of $\mathrm{p} / \mathrm{p}_{0}$. This shape could be classified as a Type I isotherm, characteristic of microporous materials, having mainly narrow micropores [53]. For HAC the isotherm shape increases continually until the end of relative pressure, indicating the presence of mesopores. Furthermore, the isotherms of both ACs display a hysteresis loop characteristic for Type IV isotherm which confirms the contribution of mesopores to their porous structure. The lack of the lower closure point in the hysteresis loop could suggest these are ink bottle-shaped mesopores [54]. However, the micropores are predominant in the studied ACs as shown in Table 6 . The $\mathrm{V}_{\mathrm{DR}} / \mathrm{V}_{\mathrm{T}}$ ratio is much higher for CAC than that for HAC (0.67 vs. 0.81). Both ACs show comparable surface area $\left(\mathrm{S}_{\mathrm{BET}}\right)$ but HAC has higher total pore volume than CAC (Table 6). The pore size distribution determined by QSDFT method reveals a more intense maximum at a pore width of $0.57 \mathrm{~nm}$ for CAC and HAC (Fig. 5b). Others peaks center at $0.79,1.01,1.54 \mathrm{~nm}$ for CAC and $0.85,1.54 \mathrm{~nm}$ for HAC are also found.

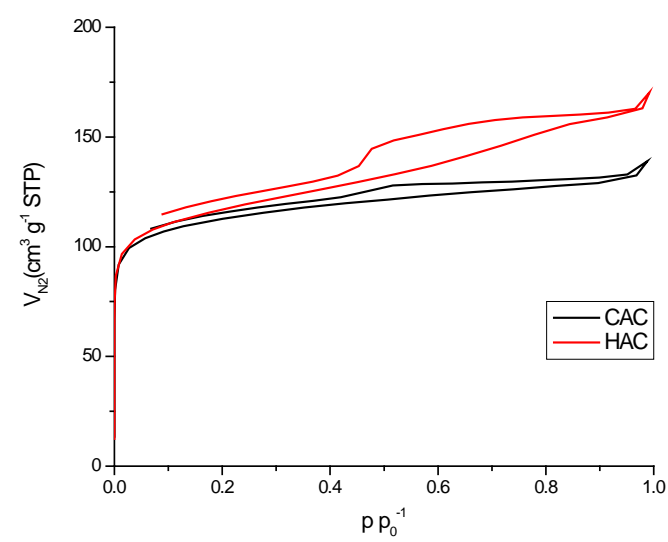

a)

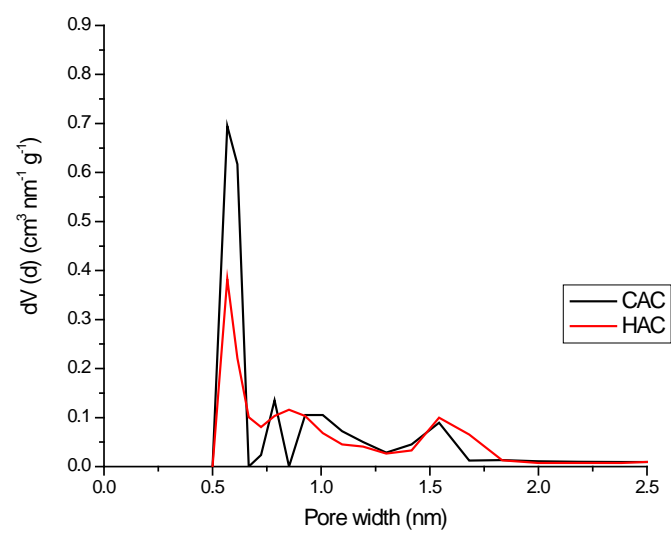

b)

Fig. 5 (a) Nitrogen adsorption-desorption isotherms at $-196^{\circ} \mathrm{C}$ and (b) QSDFT pore size distribution.

Table 6 Textural parameters for HAC and CAC

\begin{tabular}{cccccc|ccc}
\hline Sample & $\begin{array}{c}\mathrm{S} \text { BET } \\
\mathrm{m}^{2} / \mathrm{g}\end{array}$ & $\begin{array}{c}\mathrm{V}_{\mathrm{T}} \\
\mathrm{cm}^{3} / \mathrm{g}\end{array}$ & $\begin{array}{c}\mathrm{VDR}_{\mathrm{DR} 2} \\
\mathrm{~cm}^{3} / \mathrm{g}\end{array}$ & $\mathrm{VDR}_{\mathrm{D}, \mathrm{N} 2} / \mathrm{V}_{\mathrm{T}}$ & $\begin{array}{c}\mathrm{L} 0, \mathrm{~N} 2 * \\
\mathrm{~nm}\end{array}$ & $\begin{array}{c}\mathrm{V}_{\mathrm{DR}, \mathrm{CO} 2} \\
\mathrm{~cm}^{3} / \mathrm{g}\end{array}$ & $\begin{array}{c}\mathrm{S}_{0, \mathrm{CO} 2} \\
\mathrm{~m}^{2} / \mathrm{g}\end{array}$ & $\begin{array}{c}\mathrm{L}_{0, \mathrm{CO} 2} * \\
\mathrm{~nm}\end{array}$ \\
\hline HAC & 438 & 0.250 & 0.168 & 0.67 & 0.84 & 0.166 & 976 & 0.34 \\
$\mathrm{CAC}$ & 428 & 0.204 & 0.165 & 0.81 & 0.81 & 0.140 & 778 & 0.36
\end{tabular}

* $\mathrm{L}_{0}=10.8 /\left(\mathrm{E}_{0}-11.4\right)$, where $\mathrm{E}_{0}$ is the characteristic energy [45].

The prepared ACs are analyzed by sorption of $\mathrm{CO}_{2}$ to characterize ultramicropores. Fig. 6 shows the $\mathrm{CO}_{2}$ adsorption isotherms (a) and the pore size distribution determined by NLDFT method (b) in the range of ultramicropores. The ACs show a bimodal distribution of ultramicropores size with a maximum centered at $0.35 \mathrm{~nm}$, the second maximum center is located at $0.52 \mathrm{~nm}$ and $0.54 \mathrm{~nm}$ for CAC and HAC respectively. The surface area and volume achieved for the narrow micropores is greater for HAC than for CAC (Table $6)$. 


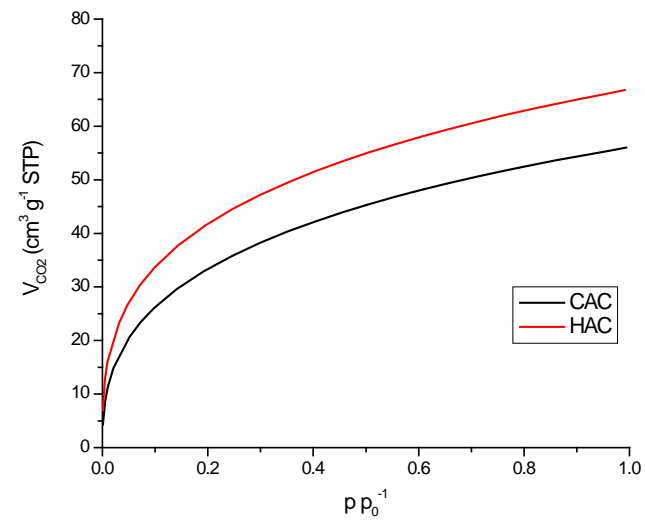

a)

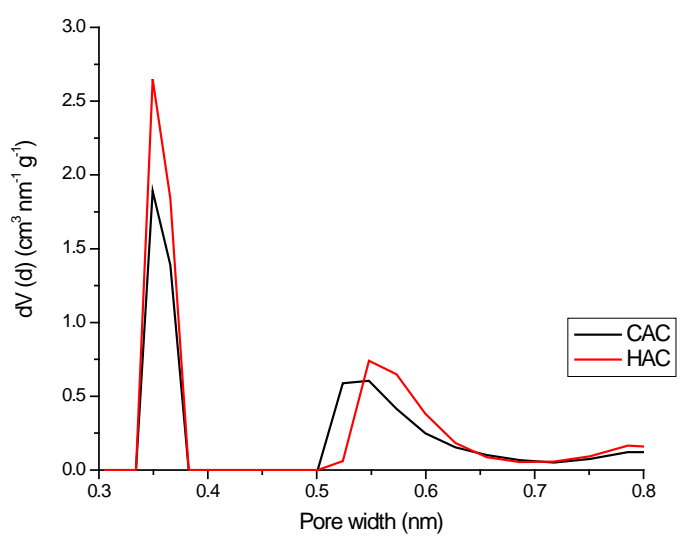

b)

Fig. 6 (a) $\mathrm{CO}_{2}$ adsorption isotherms at $0{ }^{\circ} \mathrm{C}$ and (b) NLDFT pore size distribution.

The elemental compositions of adsorbent materials at the optimal experimental conditions are shown in Table 7. The carbon and oxygen content for HAC is higher than for CAC, but the nitrogen content for CAC is a little bit higher than for HAC. However the ATR-FTIR spectra referring to oxygen containing functional groups are more intense for CAC than for HAC (Fig. 6). This partly explains the somewhat better adsorption performance of CAC towards $\mathrm{Ni}(\mathrm{II})$ than HAC, also a higher amount of nitrogen functionalities can benefit CAC more than HAC in adsorption performance towards Ni(II). The amount of sulphur is below detection limit for both samples. The literature survey shows the maximum adsorption capacities from Langmuir model and the surface area of several adsorbents (Table 8). It is noticed that there is not a linear relation between higher surface area and maximum adsorption capacities. Even when the surface area of both HAC and CAC adsorbents are lower than some of the studies reported [57, 59, 60] achieved bigger or comparable adsorption capacities toward Ni ions.

The ATR-FTIR spectra (Fig. 7) for HAC shows the bands located at $3639 \mathrm{~cm}^{-1}$ correspond with isolated hydroxyl group -OH stretch [55]; $1373 \mathrm{~cm}^{-1}$ is characteristic of phenol or tertiary alcohol -OH stretch [55]; the several peaks between 700-610 $\mathrm{cm}^{-1}$ can be attributed to aromatic $\mathrm{C}-\mathrm{H}$ and $-\mathrm{OH}$ out of plane bend [9]. CAC has peaks at $3245 \mathrm{~cm}^{-1}$ (hydroxyl group, $\mathrm{H}$-bonded -OH stretch) [55], $1511 \mathrm{~cm}^{-1}$ (aromatic C=C-C vibration stretch) [55], $1385 \mathrm{~cm}^{-1}$ (methyl $-\mathrm{CH}_{3}$ group) [55], $1038 \mathrm{~cm}^{-1}$ (primary alcohol C-O stretch or CC skeletal vibration) [55, 56], and several peaks among 900-620 $\mathrm{cm}^{-1}$ (aromatic C-H and-OH out of plane bend) [9].

Table 7 Elemental composition

\begin{tabular}{lccccc}
\hline Adsorbent & \multicolumn{5}{c}{ Elemental composition (wt. \%) } \\
material & $\mathrm{C}$ & $\mathrm{H}$ & $\mathrm{N}$ & $\mathrm{S}$ & $\mathrm{O}^{*}$ \\
\hline HAC & 59.30 & 1.34 & 0.75 & 0.00 & 13.69 \\
CAC & 48.82 & 1.21 & 0.84 & 0.00 & 11.61 \\
\hline
\end{tabular}

* by difference: $\mathrm{O} \%=(100-\mathrm{C}-\mathrm{H}-\mathrm{N}-$ ash $) \%$ 


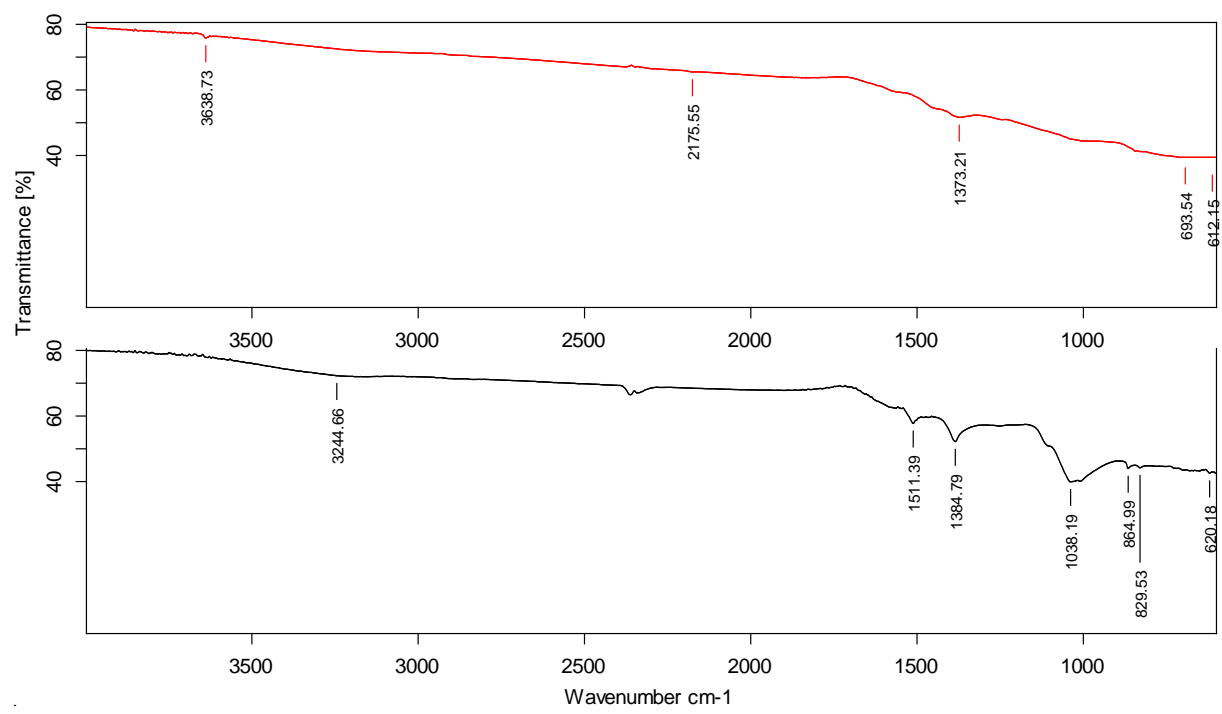

Fig. 7 ATR-FTIR spectra for $-\mathrm{HAC}$ and -CAC.

Table 8 Comparison of ACs surface area and adsorption capacity with other adsorbents

\begin{tabular}{|c|c|c|c|c|c|c|}
\hline Adsorbent & $\begin{array}{l}\mathrm{qm}(\mathrm{mg} / \mathrm{g}) \\
\text { from } \\
\text { Langmuir } \\
\text { model }\end{array}$ & $\begin{array}{l}\mathrm{S}_{\mathrm{BET}} \\
\mathrm{m}^{2} / \mathrm{g}\end{array}$ & $\begin{array}{l}\text { Solution } \\
\mathrm{pH}\end{array}$ & $\begin{array}{l}\text { Dosage } \\
(\mathrm{g} / \mathrm{L})\end{array}$ & $\begin{array}{l}\text { Concentration } \\
\text { range }(\mathrm{mg} / \mathrm{L})\end{array}$ & Reference \\
\hline $\begin{array}{l}\text { Lotus stalks derived activated } \\
\text { carbon }\end{array}$ & 31.00 & 1220 & - & 1.0 & $20-40$ & {$[57]$} \\
\hline Calcium-sepiolite & 4.81 & - & - & 1.0 & $5-100$ & [20] \\
\hline $\begin{array}{l}\text { Tetraethylenepentamine-Rosa } \\
\text { Canina-L fruits activated } \\
\text { carbon }\end{array}$ & 128.21 & - & 6 & 5.0 & $5-500$ & [9] \\
\hline $\begin{array}{l}\text { Mesoporous graphitic carbon } \\
\left.\text { nitride (mpg- } \mathrm{C}_{3} \mathrm{~N}_{4 / 1.5}\right)\end{array}$ & 19.39 & 164 & - & 1.0 & $10-100$ & {$[58]$} \\
\hline $\begin{array}{l}\text { Activated carbon from rubber } \\
\text { tires }\end{array}$ & 9.34 & 465 & - & 0.1 & $0.1-40$ & [59] \\
\hline $\begin{array}{l}\text { Activated carbon from cherry } \\
\text { kernels }\end{array}$ & 77.71 & 657 & 6 & 2.0 & $5-500$ & {$[60]$} \\
\hline $\begin{array}{l}\text { Modified magnetic chitosan } \\
\text { chelating resin }\end{array}$ & 40.15 & 55 & 5 & 1.5 & $50-400$ & [61] \\
\hline Synthetic PVA/NaX nanofibers & 342.80 & 212 & - & 0.5 & $50-1000$ & {$[22]$} \\
\hline $\begin{array}{l}\text { Activated carbon from coffee } \\
\text { husks, HAC }\end{array}$ & 102.72 & 438 & 6 & 0.5 & $10-50$ & $\begin{array}{l}\text { Present } \\
\text { study }\end{array}$ \\
\hline $\begin{array}{l}\text { Activated carbon from cocoa } \\
\text { husks, CAC }\end{array}$ & 104.99 & 428 & 6 & 0.5 & $10-50$ & $\begin{array}{l}\text { Present } \\
\text { study }\end{array}$ \\
\hline
\end{tabular}

\section{Conclusions}

The effect of temperature, activation time and water amount (used to produce steam) on yield and $\mathrm{Ni}$ (II) ions adsorption capacity of coffee and cocoa seed husks activated carbons (HAC and CAC) was successfully studied through a two-level full factorial design, analysis of variance (ANOVA) and multiple response optimization. For the yield (R1) the increment in the factors studied has a negative effect for both adsorbents, whereas for adsorption capacity (R2) the increase of the factors $A$ (temperature) and $B$ (time of activation) has a positive effect. The influence of $C$ (water amount) depends of the raw material used for the production of ACs. The main effects and their interaction have larger impact on R1 than R2. The models, the main effects and their interactions are significant, except the interaction of $A B$ and $A B C$ effects. Multiple response optimization technique for maximizing the yield and adsorption capacity gave higher values of 
R1 and R2 for CAC than the ones achieved for HAC at the optimal temperature, activation time and water amount for each adsorbent.

Isotherm data for the ACs prepared at the optimal experimental conditions is described best by the Langmuir-Freundlich model, followed by the Langmuir model. The maximum adsorption capacities achieved were higher for CAC than for HAC. CAC seems to be more suitable for the removal of $\mathrm{Ni}$ (II) than HAC.

\section{References}

[1] T. Maneerung, J. Liew, Y. Dai, S. Kawi, C. Chong, C-H. Wang, Activated carbon derived from carbon residue from biomass gasification and its application for dye adsorption: Kinetics, isotherms and thermodynamic studies, Bioresour. Technol. 200 (2016) 350-359.

[2] M. Mohamed Sihabudeen, A. Abbas Ali, A. Zahir Hussain, Removal of Heavy Metals from Ground Water using Eucalyptus Carbon as Adsorbent, Int. J. Chem. Tech. Res. 9 (2016) 254-257.

[3] F. Fu, Q. Wang, Removal of heavy metal ions from wastewaters: a review, J. Environ. Manage. 92 (2011) 407 $-418$.

[4] D. Sud, G. Mahajan, M.P. Kaur, Agricultural waste material as potential adsorbent for sequestering heavy metal ions from aqueous solutions - a review, Bioresour. Technol. 99 (2008) 6017-6027.

[5] M. Nadeem, A. Mahmood, S.A. Shahid, S.S. Shah, A.M. Khalid, G. McKay, Sorption of lead from aqueous solution by chemically modified carbon adsorbents, J. Hazard. Mater. 138 (2006) 604-613.

[6] F.-S. Zhang, J.O. Nriagu, H. Itoh, Mercury removal from water using activated carbons derived from organic sewage sludge, Water Res. 39 (2005) 389-395.

[7] A.M. Youssef, T. El-Nabarawy, S.E. Samra, Sorption properties of chemically-activated carbons: 1. Sorption of cadmium (II) ions, Colloids Surf. A Physicochem. Eng. Asp. 235 (2004) 153-163.

[8] H.Yanagisawa, Y. Matsumoto, M. Machida, Adsorption of $\mathrm{Zn}(\mathrm{II})$ and $\mathrm{Cd}(\mathrm{II})$ ions onto magnesium and activated carbon composite in aqueous solution, Appl. Surf. Sci. 256 (2010) 1619 - 1623.

[9] M. Ghasemi, M.Z. Khosroshahy, A.B. Abbasabadi, N. Ghasemi, H. Javadian, M. Fattahi, Microwave-assisted functionalization of Rosa Canina- $\mathrm{L}$ fruits activated carbon with tetraethylenepentamine and its adsorption behaviour toward Ni (II) in aqueous solution: Kinetic, equilibrium and thermodynamic studies, Powder Technol. 274 (2015) 362-371.

[10] A. Üçer, A. Uyanik, S.F. Aygün, Adsorption of Cu(II), Cd(II), Zn(II), Mn(II) and Fe(III) ions by tannic acid immobilised activated carbon, Sep. Purif. Technol. 47 (2006) 113 - 118.

[11] H.G. Park, T.W. Kim, M.Y. Chae, I.K. Yoo, Activated carbon-containing alginate adsorbent for the simultaneous removal of heavy metals and toxic organics, Process Biochem. 42 (2007) 1371 - 1377.

[12] C.K. Ahn, D. Park, S.H. Woo, J.M. Park, Removal of cationic heavy metal from aqueous solution by activated carbon impregnated with anionic surfactants, J. Hazard. Mater. 164 (2009) 1130 - 1136.

[13] R. Gottipati, S. Mishra, Process optimization of adsorption of $\mathrm{Cr}(\mathrm{VI})$ on activated carbons prepared from plant precursors by a two-level full factorial design, Chem. Eng. Journal 160 (2010) 99-107.

[14] M. Ahmedna, W.E. Marshall, R.M. Rao, Production of granular activated carbons from select agricultural by-products and evaluation of their physical, chemical and adsorption properties, Bioresour. Technol. 71 (2000) 113-123.

[15] U. Kumar, Agricultural products and by-products as a low cost adsorbent for heavy metal removal from water and wastewater: A review, Sci. Res. Essays. 1 (2006) 33-37.

[16] L.C.A. Oliveira, E. Pereira, I.R. Guimaraes, A. Vallone, M. Pereira, J.P. Mesquita, K. Sapag, Preparation of activated carbons from coffee husks utilizing $\mathrm{FeCl}_{3}$ and $\mathrm{ZnCl}_{2}$ as activating agents, J. Hazard. Mater. 165 (2009) 87-94.

[17] M. Gonçalves, M.C. Guerreiro, L.C.A. Oliveira, C. Solar, M. Nazarro, K. Sapag, Micro Mesoporous Activated Carbon from Coffee Husk as Biomass Waste for Environmental Applications, Waste Biomass Valor 4 (2013) 395-400.

[18] S. Rovani, A.G. Rodríguez, L.F. Medeiros, R. Cataluña, E.C. Lima, A.N. Fernández. Synthesis and characterisation of activated carbon from agroindustrial waste-Preliminary study of $17 \beta$-estradiol removal from aqueous solution, J. of Environ. Chem. Eng. 4 (2016) 2128-2137.

[19] J.M. Dias, M.C.M. Alvim-Ferraz, M.F. Almeida, J. Rivera-Utrilla, M. Sánchez-Polo, Waste materials for activated carbon preparation and its use in aqueous-phase treatment: A review, J. Environ. Manage. 85 (2007) 833-846.

[20] A. Sheikhhosseini, M. Shirvani, H. Shariatmadari, F. Zvomuya, B. Najafic. Kinetics and thermodynamics of nickel sorption to calcium-palygorskite and calcium-sepiolite: A batch study, Geoderma 217-218 (2014) 111117. 
[21] Y.S. Dzyazko, L.N. Ponomaryova, Y.M. Volfkovich, V.V. Trachevskii, A.V. Palchik, Ion-exchange resin modified with aggregated nanoparticles of zirconium hydrophosphate. Morphology and functional properties, Microporous Mesoporous Mater. 198 (2014) 55-62.

[22] L.R. Rad, A. Momeni, B.F. Ghazani, M. Irani, M. Mahmoudi, B. Noghreh, Removal of Ni2+ and Cd2+ ions from aqueous solutions using electrospun PVA/zeolite nanofibrous adsorbent, Chem. Eng. J. 256 (2014) 119-127. [23] A.Z.M. Badruddoza, Z. B. Zakir Shawon, T.W. Jin Daniel, K. Hidajat, M. Shahab Uddin, Fe3O4/cyclodextrin polymer nanocomposites for selective heavy metals removal from industrial wastewater, Carbohydr. Polym. 91 (2013) 322-332.

[24] A. Afkhami, M. Saber-Tehrani, H. Bagheri, Simultaneous removal of heavy-metal ions in wastewater samples using nano-alumina modified with 2,4-dinitrophenylhydrazine, J. Hazard. Mater. 181 (2010) 836-844.

[25] WHO, Guidelines for drinking-water quality. In: Chemical Fact Sheets. World Health Organization, Geneva 2004.

[26] WHO, Guidelines for drinking-water quality, 1st Addedum. In: Chemical Fact Sheets. World Health Organization, Geneva 2006.

[27] M. Adib Yahya, Z. Al-Qodah, C.W. Zanariah Ngah. Agricultural bio-waste materials as potential sustainable precursors used for activated carbon production: a review, Renew. Sust. Energ. Rev. 46 (2015) 218-235.

[28] Z.R. Lazic, Ed., Design of Experiments in Chemical Engineering, Wiley-VCH Verlag GmbH \& Co. KGaA, Weinheim, 2004.

[29] T. Cornelissen, J. Yperman, G. Reggers, S. Schreurs, R. Carleer, Flash co-pyrolysis of biomass with polylactic acid. Part I: influence on bio-oil yield and heating value, Fuel 87 (2008) 1031-1041.

[30] K. Vanreppelen, S. Vanderheyden, T. Kuppens, S. Schreurs, J. Yperman, R. Carleer, Activated carbon from pyrolysis of brewer's spent grain production and adsorption properties, Waste Manage. Res. 32 (2014) 634-645.

[31] D.C. Montgomery, Design and Analysis of Experiments, 4th ed., John Wiley and Sons, New York, 1997.

[32] E.C. Harrington, The desirability function, Ind. Qual. Control 21 (1965) 494-498.

[33] G. Derringer, R. Suich, Simultaneous optimization of several response variables, J. Qual. Technol. 12 (1980) 214-219.

[34] M. Fereidouni, A. Daneshi, H. Younesi, Biosorption equilibria of binary Cd(II) and Ni(II) systems onto Saccharomyces cerevisiae and Ralstonia eutropha cells: Application of response surface methodology, J. Hazard. Mater. 168 (2009) 1437-1448.

[35] M. Mourabet, A. El Rhilassi, H. El Boujaady, M. Bennani-Ziatni, R. El Hamri, A. Taitai, Removal of fluoride from aqueous solution by adsorption on Apatitic tricalcium phosphate using Box-Behnken design and desirability function, Appl. Surf. Sci. 258 (2012) 4402-4410.

[36] M. Loredo-Cancino, E. Soto-Regalado, F.J. Cerino-Córdova, R.B. García-Reyes, A.M. García-León, M.T. Garza-González, Determining optimal conditions to produce activated carbon from barley husks using single or dual optimization, J. Environ. Manage. 125 (2013) 117-125.

[37] J.N. Sahu, J. Acharya, B.C. Meikap, Optimization of production conditions for activated carbons from Tamarind wood by zinc chloride using response surface methodology, Bioresour. Technol. 101 (2010) 19741982.

[38] M. Roosta, M. Ghaedi, A. Daneshfar, R. Sahraei, Experimental design based response surface methodology optimization of ultrasonic assisted adsorption of safaranin $\mathrm{O}$ by tin sulphide nanoparticle loaded on activated carbon, Spectrochim. Acta, Part A 122 (2014) 223-231.

[39] S. Khodadoust, M. Hadjmohammadi, Determination of N-methylcarbamate insecticides in water samples using dispersive liquid-liquid microextraction and HPLC with the aid of experimental design and desirability function, Anal. Chim. Acta 699 (2011) 113-119.

[40] L.Vera Candioti, M.M. De Zan, M.S. Cámara, H.C. Goicoechea, Experimental design and multiple response optimization. Using the desirability function in analytical methods development, Talanta 124 (2014) 123-138.

[41] M. Hernandez Rodriguez, J. Yperman, R. Carleer, J. Maggen, D. Dadi, G. Gryglewicz, B.V der Bruggen, J.F. Hernández, A.O. Calvis, Adsorption of Ni(II) on spent coffee and coffee husk based activated carbon, J. Environ. Chem. Eng. 6 (2018) 1161-1170.

[42] W.E. Oliveira, A. S. Franca, L.S. Oliveira, S.D. Rocha, Untreated coffee husks as biosorbents for the removal of heavy metals from aqueous solutions, J. Hazard. Mater. 152 (2008) 1073-1081.

[43] K.Y. Foo, B.H. Hameed, Insights into the modeling of adsorption isotherm systems, Chem. Eng. J. 156 (2010) 2-10.

[44] S. Kundu, A.K. Gupta, Arsenic adsorption onto iron oxide-coated cement (IOCC): regression analysis of equilibrium data with several isotherm models and their optimization, Chem. Eng. J. 122 (2006) 93-106.

[45] A.B. Pérez-Marín, V. Meseguer Zapata, J.F. Ortuno, M. Aguilar, J. Sáez, M. Llorens, Removal of cadmium from aqueous solutions by adsorption onto orange waste, J. Hazard. Mater. 139 (2007) 122-131. 
[46] K.R. Hall, L.C. Eagleton, A. Acrivos, T. Vermeule, Pore and solid-diffusion kinetics in fixed-bed adsorption under constant-pattern conditions, Ind. Eng. Chem. Fund. 5 (1966) 212-223.

[47] M. El-Sadaawy, O. Abdelwahab, Adsorptive removal of nickel from aqueous solutions by activated carbons from doum seed (Hyphaenethebaica) coat, Alexandria Eng. J. 53 (2014) 399-408.

[48] G.P. Jeppu, T. Prabhakar Clement, A modified Langmuir-Freundlich isotherm model for simulating pHdependent adsorption effects, J. Contam. Hydrol. 129-130 (2012) 46-53.

[49] F. Stoeckil, E. Daguerre, A. Guillot, The development of micropore volumes and widths during physical activation of various precursors, Carbon 37 (1999) 2075-2077.

[50] A.V. Neimark, Y. Lin, P.I. Ravikovitch, M. Thommes, Quenched solid density functional theory and pore size analysis of micro-mesoporous carbons, Carbon 47 (2009) 1617-1628.

[51] F. Stoeckli, M.V. Lopez-Ramon, C. Moreno-Castilla, Adsorption of phenolic compounds from aqueous solutions, by activated carbons, described by the Dubinin-Astakhov equation, Langmuir 17 (2001) 3301-3306.

[52] P. Tarazona, M. Bettolo Marconi., R. Evans, Phase equilibria of fluid interfaces and confined fluids: nonlocal versus local density functionals, Mol. Phys. 60 (1987) 573.

[53] M. Thommes, K. Kaneko, A. V. Neimark, J. P. Olivier, F. Rodriguez-Reinoso, J. Rouquerol, K. S.W. Sing, Physisorption of gases, with special reference to the evaluation of surface area and pore size distribution (IUPAC Technical Report), Pure Appl. Chem. 87 (2015) 1051-1069.

[54] X.S.J. Gregg, K.S.W. Sing, Adsorption, Surface Area and Porosity, Academic Press, London 1997.

[55] J. Coates, Interpretation of Infrared Spectra, A Practical Approach, Encyclopedia of Analytical Chemistry, John Wiley \& Sons Ltd, Chichester, 2006.

[56] A. Ewecharoen, P. Thiravetyan, E. Wendel, H. Bertagnolli, Nickel adsorption by sodium polyacrylate-grafted activated carbon, J. Hazard. Mater. 171 (2009) 335-339.

[57] L. Huang, Y. Sun, T. Yang, L. Li, Adsorption behavior of Ni (II) on lotus stalks derived active carbon by phosphoric acid activation, Desalination 268 (2011) 12-19.

[58] G. Xin, Y. Xia, Y. Lv, L. Liu, B. Yu, Investigation of Mesoporous Graphitic Carbon Nitride as the Adsorbent to Remove Ni (II) Ions, Water Environ. Res. 88 (2016) 318-324.

[59] M.N. Siddiquia, H.H. Redhwib, A.A. Al-Saadia, M. Rajeha, T.A. Saleh, Kinetic and computational evaluation of activated carbon produced from rubber tires toward the adsorption of nickel in aqueous solutions, Desalin. Water Treat. 57 (2016) 17570-17578.

[60] S. Pap, J. Radonic, S. Trifunovic, D. Adamovic, I. Mihajlovic, M.V. Miloradov, M.T. Sekulic, Evaluation of the adsorption potential of eco-friendly activated carbon prepared from cherry kernels for the removal of $\mathrm{Pb} 2+$, Cd2+ and Ni2+ from aqueous wastes. J. Environ. Manage. 184 (2016) 297-306.

[61] M. Monier, D.M. Ayad, Y. Wei, A.A. Sarhan, Adsorption of $\mathrm{Cu}(\mathrm{II}), \mathrm{Co}(\mathrm{II})$, and Ni(II) ions by modified magnetic chitosan chelating resin. J. Hazard. Mater. 177 (2010) 962-970. 